\title{
Liraglutide counteracts obesity and glucose intolerance in a mouse model of glucocorticoid-induced metabolic syndrome
}

\author{
Liselotte Fransson ${ }^{1}$, Cristiane dos Santos ${ }^{2}$, Petra Wolbert ${ }^{1}$, Åke Sjöholm ${ }^{1,3,4}$, Alex Rafacho ${ }^{2}$ and Henrik Ortsäter ${ }^{1,5^{*}}$
}

\begin{abstract}
Background: Glucocorticoid excess is commonly associated with diabetogenic effects, including insulin resistance and glucose intolerance. The effects of the long-term glucagon-like peptide 1 receptor agonist treatment on the metabolic syndrome-like conditions are not yet fully elucidated. Thus, we aimed to test whether long-term liraglutide treatment could be effective as a therapy to counteract the metabolic dysfunctions induced by chronic glucocorticoid exposure.
\end{abstract}

Methods: Mice were given corticosterone or vehicle via their drinking water for five consecutive weeks. In addition, mice were treated with once-daily injections of either PBS or liraglutide.

Results: Liraglutide treatment slowed progression towards obesity and ectopic fat deposition in liver that otherwise occurred in corticosterone-treated mice. The drug reduced the increment in serum insulin caused by corticosterone, but did not affect the reduction of insulin sensitivity. Furthermore, liraglutide improved glucose control in mice exposed to corticosterone as evident by a delay in the progression towards post-prandial hyperglycemia and enhanced glucose clearance during a glucose tolerance test. Glucose-stimulated C-peptide levels were higher in those mice that had received liraglutide and corticosterone compared to mice that had been treated with corticosterone alone, indicating a positive role of liraglutide for beta-cell function. Morphometric analysis revealed increased beta- and alpha-cell masses that were associated with more Ki67-positive islet cells in corticosterone-treated mice irrespective of whether they were co-treated with liraglutide or not. Liraglutide had no discernible effect on alpha-cell mass.

Conclusion: Liraglutide can be beneficial for subjects at risk of developing metabolic complications as a result of glucocorticoid excess.

Keywords: Corticosterone, Diabetes, Liraglutide, Metabolic syndrome, Insulin, Beta-cell, Islet

\section{Background}

During long term treatment with glucocorticoids (GCs), many patients develop various degrees of glucose intolerance, some progressing into frank diabetes, a condition commonly known clinically as "steroid diabetes" [1]. Additionally, worsening of glycemic control in patients with known type 2 diabetes mellitus (T2DM) on GC therapy is also a clinically well-known phenomenon. The reasons for the impaired glucose tolerance are probably

\footnotetext{
* Correspondence: henrik.ortsater@ki.se

'Department of Clinical Science and Education, Södersjukhuset, Karolinska Institutet, Research Center Floor 3, 118 83, Stockholm, Sweden

${ }^{5}$ Research Unit, Södertälje Hospital, SE-152 86, Södertälje, Sweden

Full list of author information is available at the end of the article
}

multifactorial, and the precise nature of the mechanisms contributing remains elusive. The insulin-producing pancreatic beta-cell may be extra susceptible to GC excess, since both iatrogenic Cushing syndrome and GCinduced diabetes in animal models are associated with loss of glucose-stimulated insulin secretion (GSIS), and GC immunosuppressive treatment adversely affects islet transplantation outcome [2]. In animal models susceptible to GC treatment, dexamethasone exposure causes GLUT-2 degradation, thereby impeding beta-cell glucose sensing [3] and increases islet glucose cycling as a consequence of augmented glucose-6-phosphatase activity [4,5]. In vitro, GCs exert several negative effects on beta-cell function including reduced GSIS and increased alpha-2 
adrenergic receptor response [6], increased activity of $\mathrm{K}_{\mathrm{v}} 1.5$ channel (repolarizing potassium channel) [7], endoplasmic reticulum dysfunction [8], and increased beta-cell apoptosis $[9,10]$. Since the human insulin gene contains GC-sensitive transcriptional elements [11], it may be susceptive to deleterious effects of GCs. Beta-cell susceptibility to GCs may also be relevant in the natural unfolding of diabetes, since mice overexpressing the GC receptor restricted to the beta-cell develop early beta-cell failure, glucose intolerance and later in life overt diabetes $[4,5]$. Humans with impaired beta-cell function (low insulin responders) are predisposed to become overtly diabetic during GC therapy [12]. Clinically, steroid diabetes or worsened glycemic control in diabetic subjects is usually treated with insulin injections, oftentimes mixtures containing a high proportion of a direct acting insulin analogue to curb prandial glycemia. However, such regime may result in undesirable side effects. The risk of incurring hypoglycemia, weight gain and adiposity - on top of what is the result of GC therapy - is a significant drawback of insulin treatment. Recently, another class of antidiabetic agents, incretin-based therapy, has been made available $[13,14]$. This novel treatment modality is based upon activation of the receptor for glucagon-like peptide 1 (GLP-1), which leads to enhanced GSIS, glucagon suppression and other antidiabetic effects $[13,14]$. GLP-1 is synthesized in enteroendocrine L-cells and is released post-prandially in proportion to caloric intake. Especially carbohydrate and fat seem to be effective stimuli for GLP1 secretion [15]. GLP-1 drugs, in contrast to insulin, are devoid of risk for hypoglycemia and weight gain. Exendin4, the first generation GLP-1 receptor (GLP-1R) agonist was recently shown to improve beta-cell function in healthy men treated for two days with prednisolone [16]. Similarly, Matsuo et al. reported on four cases of patients with type 2 diabetes with worsened glycemic control due to GCs who were successfully treated with exendin-4 administration [17]. Although these studies indicate beneficial glycemic effects of GLP-1 receptor activation after GC treatment, they neither address the ability of these drugs to counteract the long-term effects of GC treatment. In the present work, we aimed at addressing this issue in an animal model of steroid diabetes by using liraglutide, an efficacious second generation GLP-1 analogue in clinical use $[18,19]$ and to study the mechanisms behind any protective effect exerted by liraglutide.

\section{Methods}

\section{Animals and treatment}

Experiments were performed on 8-week-old male C57Bl/6J mice (Nova, Sollentuna Sweden) which were fed ad libitum and housed in 12 hours of light/12 hours of dark cycles. The study was performed according to the guidelines of Karolinska Institutet and approved by the Stockholm South animal ethics committee (S49-12). Animals were randomly assigned to either receive corticosterone $(100 \mu \mathrm{g} / \mathrm{ml}$, [Sigma, St Louis, MO, USA]) or vehicle ( $1 \%$ ethanol) via their drinking water. This corticosterone regimen is known to produce a valuable mouse model with metabolic syndrome features [20,21]. In addition, half of the mice in each group were given once daily s.c. injections (between 9:00 and 10:00 am) of liraglutide (Novo Nordisk A/S, Bagsvaerd, Denmark) and the other half were given PBS in the same manner. To improve liraglutide tolerability, the drug was given in escalating doses starting at $0.15 \mathrm{mg}$ per $\mathrm{kg}$ body weight with a daily increment of $0.025 \mathrm{mg} / \mathrm{kg}$ until the final dose of $0.3 \mathrm{mg}$ per $\mathrm{kg}$ body weight was reached. This dose was maintained during the remaining part of the study period.

Food intake, body weight, and blood glucose levels in random-fed mice were monitored weekly, using a handheld glucometer (One-Touch Ultra 2; LifeScan, Milpitas, CA, USA). Every week blood was collected for serum insulin level evaluations with ELISA (Mercodia, Uppsala, Sweden). Blood samples for determination of glucose and insulin concentrations were taken in the morning in non-fasted animals prior to administration of liraglutide or PBS. The total exposure period was five weeks during which the animals were subjected to insulin or glucose tolerance tests (IPinsTT and IPGTT, respectively) as described below. After the five weeks of treatment, mice were sacrificed and organs were collected. Pancreatic glands were dissected and fixated in $4 \%$ phosphatebuffered paraformaldehyde, paraffin-embedded and sectioned for immunohistochemistry. Fat deposits and spleen were gently removed and weighed, and liver fragments were snap-frozen for later sectioning and oil-red-O staining. Blood was collected by heart puncture for later analyses of serum non-esterified fatty acids (NEFA), total cholesterol and triglycerides (analyzed at Karolinska University Laboratory at Södersjukhuset, Stockholm and Center for Inherited Metabolic Diseases, Karolinska University Hospital, Solna) and for corticosterone (corticosterone EIA, Enzo Life Sciences, Lausen, Switzerland) and corticotropin (mouse corticotropin ELISA, Wuhan EIAab Science, Wuhan, China).

\section{IPinsTT and IPGTT}

IPinsTT and IPGTT were performed during the fourth and fifth week of treatment, respectively. For IPinsTT and IPGTT, mice were fasted one or six hours, respectively, and then injected IP with insulin (2 IU/ $\mathrm{kg}$ body weight) or glucose (1.5 g/ $\mathrm{kg}$ body weight). On the day of the tolerance tests, liraglutide was injected as usual in the morning, 6 hours before the experiments. The fasting time before the IPinsTT was kept short to avoid hypoglycemia and counter regulatory hormone secretion. Mice received the standard injections of PBS or liraglutide on the same 
days as the tolerance tests were performed. Blood glucose was monitored before and after the insulin or glucose injections. During the IPGTT blood was also collected before and at 15 and 30 minutes post injection for determination of C-peptide levels, which were evaluated using ELISA (Alpco Diagnostics, Salem, NH, USA).

\section{Oil-red-O staining}

Frozen fragments of liver were embedded in NEG-50 (Thermo Scientific, Waltham, MA, USA). Cryo-sections $(12 \mu \mathrm{m})$ were obtained from different parts of the tissues and stained for neutral lipids using oil-red-O as previously described [22]. Quantification of lipid droplets was done in accordance with [22].

\section{Quantitative approaches in endocrine pancreas}

To study the morphometric parameters of endocrine pancreas, 5-6 pancreatic glands from each group were excised and processed according to a previous description [23] except that 4\% phosphate-buffered paraformaldehyde was used as fixative solution.

\section{Immunostaining}

Islet distribution of insulin, glucagon and Ki67 were analyzed as previously described [23].

\section{Alpha- and beta-cell mass}

Alpha-cell and beta-cell mass was determined by point counting morphometry on each pancreas section immunostained for either glucagon or insulin, as previously described [24]. Each section was systematically scored with a grid of 130 points (final magnification $\times 100$ ) using the image processing and analysis software - ImageJ (freely available at http://rsbweb.nih.gov/ij/). The numbers of intercepts over beta-cells, endocrine non-beta-cells and exocrine pancreatic tissue were counted. The beta-cell relative volume was calculated by dividing the intercepts over beta-cells by the intercepts over the total pancreatic tissue; the beta-cell mass was then estimated by multiplying the beta-cell relative volume by the total pancreas weight. The same methodology was applied for counting alpha-cell mass in sections immunostained for glucagon.

\section{Islet-cell proliferation}

Averaged islet-cell proliferation was obtained by counting total islet-cell stained for insulin and Ki67 using the same software cited above. All islets found in each pancreas section were sampled (1,714 \pm 218 beta-cell nuclei per group). The rate of islet-cell proliferation was expressed as the proportion of Ki67-positive cells of total islet cells [24].

\section{Statistical analysis}

Data are presented as mean \pm s.e.m. The appropriate $t$-test, or one-way ANOVA followed by Bonferroni post- hoc test, was used as required to identify differences between groups, using GraphPad Prism 5.0 software. A value of $\mathrm{p}<0.05$ was considered statistically significant.

\section{Results \\ Once daily injections of liraglutide delay body weight gain and obesity in corticosterone-treated mice}

The present study includes four different experimental groups. Male $\mathrm{C} 57 \mathrm{Bl} / 6 \mathrm{~J}$ mice were randomized to receive either vehicle ( $1 \%$ ethanol) or $100 \mu \mathrm{g} / \mathrm{ml}$ of corticosterone via their drinking water. In addition, both vehicle- and corticosterone-treated mice were given once daily injections of either PBS or liraglutide (final dose $0.3 \mathrm{mg} / \mathrm{kg}$ body weight). Vehicle-treated mice gained on average $2.5 \pm 0.3 \mathrm{~g}$ weight over the five week study period. Mice receiving corticosterone via their drinking water had an augmented net body weight gain that was significant already after two weeks of treatment (Figure 1A) and was associated with a higher food intake (Figure 1B). Once daily injections with liraglutide did not influence food intake or body weight gain in vehicle-treated animals, but clearly slowed body weight gain in corticosterone-treated mice (Figure 1A). As expected, administration of corticosterone via the drinking water led to supraphysiological levels of the steroid hormone and suppressed endogenous levels of corticotropin (Table 1). Liraglutide treatment did not modulate serum levels of corticosterone or corticotropin neither in mice receiving vehicle nor corticosterone. This model of GC excess develops enlarged fat deposits and dyslipidemia (Figure $1 \mathrm{C}$ and Table 1). In concordance with a reduced body weight gain, fat deposit weights were generally lower in liraglutide-treated mice (Figure 1C). In contrast, treatment with liraglutide had minor, if any, effects on serum levels of NEFA, triglycerides and total cholesterol (Table 1). Chronic treatment with corticosterone is known to reduce spleen size [25]. In vehicle-treated mice that had received injections of PBS the spleen weight was $0.3 \pm 0.04 \%$ of total body weight. Treatment with corticosterone reduced spleen weight to $0.13 \pm 0.01 \%$ of total body weight $(\mathrm{p}<0.01)$. However, once daily injections of liraglutide did not influence spleen weight in either vehicle- or corticosterone-treated mice, showing that liraglutide did not reduce corticosterone effects in mice in general. As corticosterone-exposed mice accumulate ectopic fat [26], which is known to contribute to deranged glucose control [27], we also monitored accumulation of neutral lipids in cryo-sections of liver tissue via oil-red-O staining. Indeed, corticosteronetreated mice had a 6.5-fold increase in liver oil-red-O staining compared to vehicle-treated mice (Figures 1D and E). While liraglutide had no effect on liver steatosis in vehicle-treated mice, the drug reduced hepatic neutral lipid content by approximately $40 \%$ in corticosteronetreated mice (Figures 1D and E). In conclusion, once-daily 


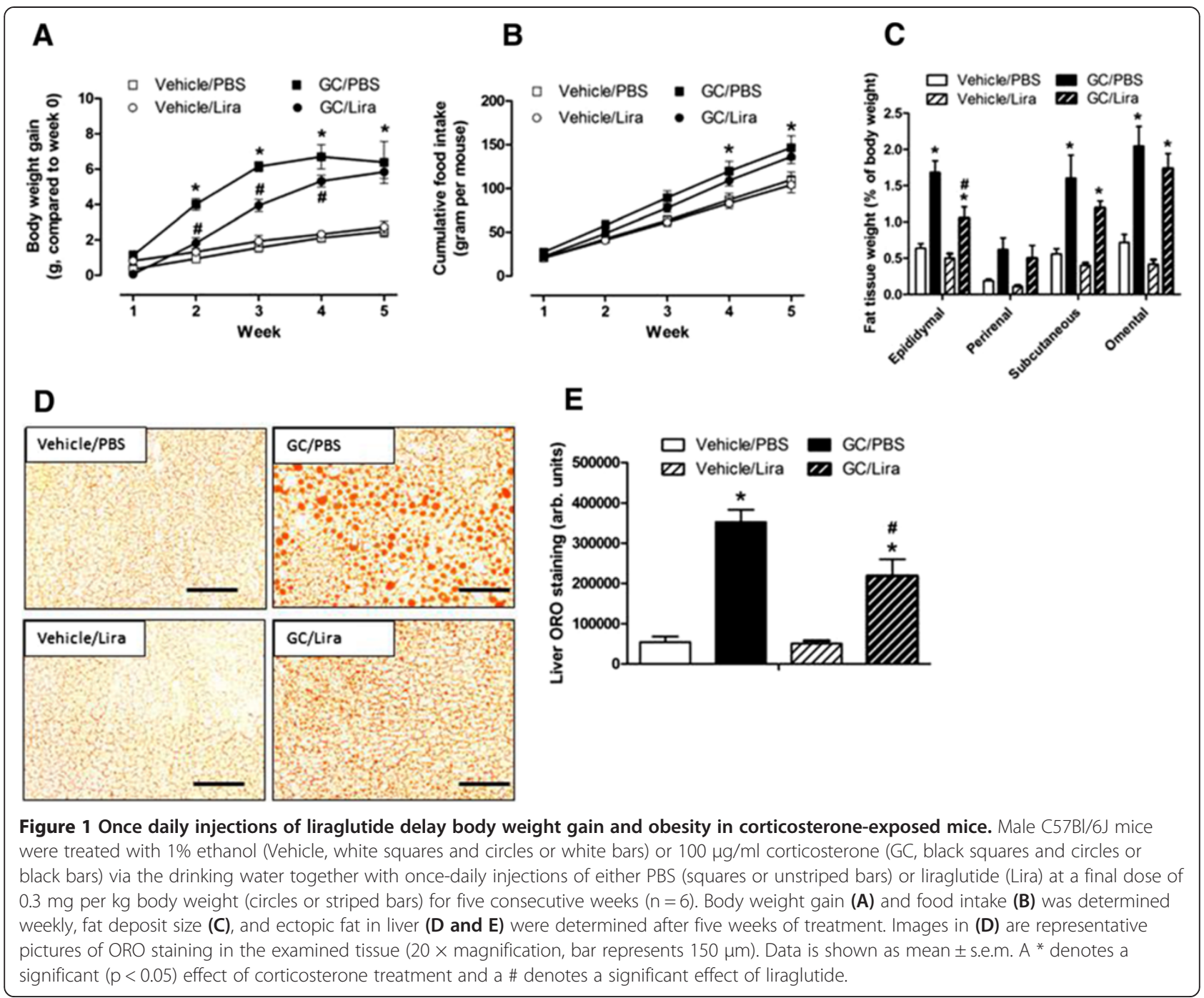

injections of liraglutide slow the progression towards obesity and ectopic fat deposition in liver that otherwise occurs during administration of corticosterone to mice.

\section{Liraglutide improves glucose tolerance in corticosterone-treated mice}

To investigate the effects of liraglutide on glucose control in corticosterone-treated mice, serum insulin and blood glucose levels were measured every week in random-fed mice throughout the study period. Corticosterone given via the drinking water time-dependently increased serum insulin levels (Figure 2A) as compared to vehicle-treated mice, indicating reduction of peripheral insulin sensitivity. Liraglutide attenuated circulating insulin levels by approximately $35 \%$ in corticosterone-treated mice (Figures 2A and B). Administration of corticosterone via the drinking water did not induce fasting hyperglycemia. The fasting blood glucose levels after five weeks of treatment were $8.1 \pm 0.7 \mathrm{mmol} / \mathrm{L}$ and $9.0 \pm 1.4 \mathrm{mmol} / \mathrm{L}$ in vehicle and corticosterone treated mice, respectively (not significant). In contrast, mice treated with corticosterone demonstrated impaired glucose control in the fed state. After two weeks of treatment with corticosterone, blood glucose levels in random-fed mice were significantly higher as compared to vehicle-treated mice and after three weeks of treatment the blood glucose levels were above $20 \mathrm{mmol} / \mathrm{L}$ in corticosterone-treated mice (Figure 2C). Once-daily injections of liraglutide improved glucose control in mice exposed to corticosterone. Fed blood glucose levels were normal in mice receiving liraglutide in combination with corticosterone up until the third week of treatment (Figure 2C). Integrated over the total five week study period the GLP-1R agonist reduced hyperglycemia in random fed mice by $30 \%$ (Figure 2D). However, after five weeks of GC exposure liraglutide was no longer able to prevent the hyperglycemia in this cohort of mice. To further evaluate the effects of liraglutide on glucose control in corticosterone-exposed mice we performed an 
Table 1 Serum parameters in mice

\begin{tabular}{ccccc}
\hline & \multicolumn{4}{c}{ Experimental groups } \\
\cline { 2 - 5 } & Vehicle/PBS & GC/PBS & Vehicle/Lira & GC/Lira \\
\hline Corticosterone $(\mathrm{ng} / \mathrm{ml})$ & $6.72 \pm 2.29$ & $46.56 \pm 4.78^{*}$ & $7.83 \pm 2.18$ & $65.29 \pm 10.6^{*}$ \\
Corticotropin $(\mathrm{pg} / \mathrm{ml})$ & $122 \pm 14$ & $45 \pm 8^{*}$ & $134 \pm 18$ & $39 \pm 14^{*}$ \\
$\quad$ NEFA $(\mathrm{mmol} / \mathrm{L})$ & $0.86 \pm 0.04$ & $1.30 \pm 0.11^{*}$ & $0.92 \pm 0.07$ & $1.22 \pm 0.14$ \\
Cholesterol $(\mathrm{mmol} / \mathrm{L})$ & $2.84 \pm 0.19$ & $5.29 \pm 0.46^{*}$ & $2.61 \pm 0.12$ & $4.16 \pm 0.68^{*}$ \\
Triglycerides $(\mathrm{mmol} / \mathrm{L})$ & $1.26 \pm 0.06$ & $4.13 \pm 1.10^{*}$ & $1.39 \pm 0.15$ & $2.98 \pm 0.75$ \\
\hline
\end{tabular}

Male $\mathrm{C} 57 \mathrm{Bl} / 6 \mathrm{~J}$ mice were treated with $1 \%$ ethanol (vehicle) or $100 \mu \mathrm{g} / \mathrm{ml}$ corticosterone (GC) via their drinking water together with once-daily injections of either PBS or liraglutide (Lira) at a final dose of $0.3 \mathrm{mg}$ per kg body weight for five consecutive weeks $(n=5-6)$. At the end of the study, blood was collected by heart puncture and serum was obtained. Serum levels for the indicated parameters are shown as mean \pm s.e.m. A * denotes a significant $(p<0.05)$ effect of corticosterone treatment.

IPinsTT and an IPGTT after four and five weeks of treatment, respectively. Treatment with corticosterone significantly reduced the blood glucose lowering effect of insulin (Figures $3 \mathrm{~A}$ and $\mathrm{B}$ [B is AUC]). Treatment with liraglutide neither influenced insulin sensitivity in corticosterone- nor in vehicle-treated animals. Following IPGTT, glucose tolerance was reduced in corticosteronetreated mice as compared to vehicle-treated mice (Figures 3C and D [D is AUC]). Once daily injections of liraglutide significantly improved glucose tolerance in both vehicle- and corticosterone-treated animals, with the largest effect obtained in corticosterone-treated mice (Figures 3C and D). C-peptide levels during the IPGTT were analyzed, showing that before glucose injection both cohorts of corticosterone-treated mice had higher levels of $\mathrm{C}$-peptide as compared to their respective control groups, which reflects the higher basal insulin levels (Figure 3E). During the in vivo GSIS (IPGTT), the
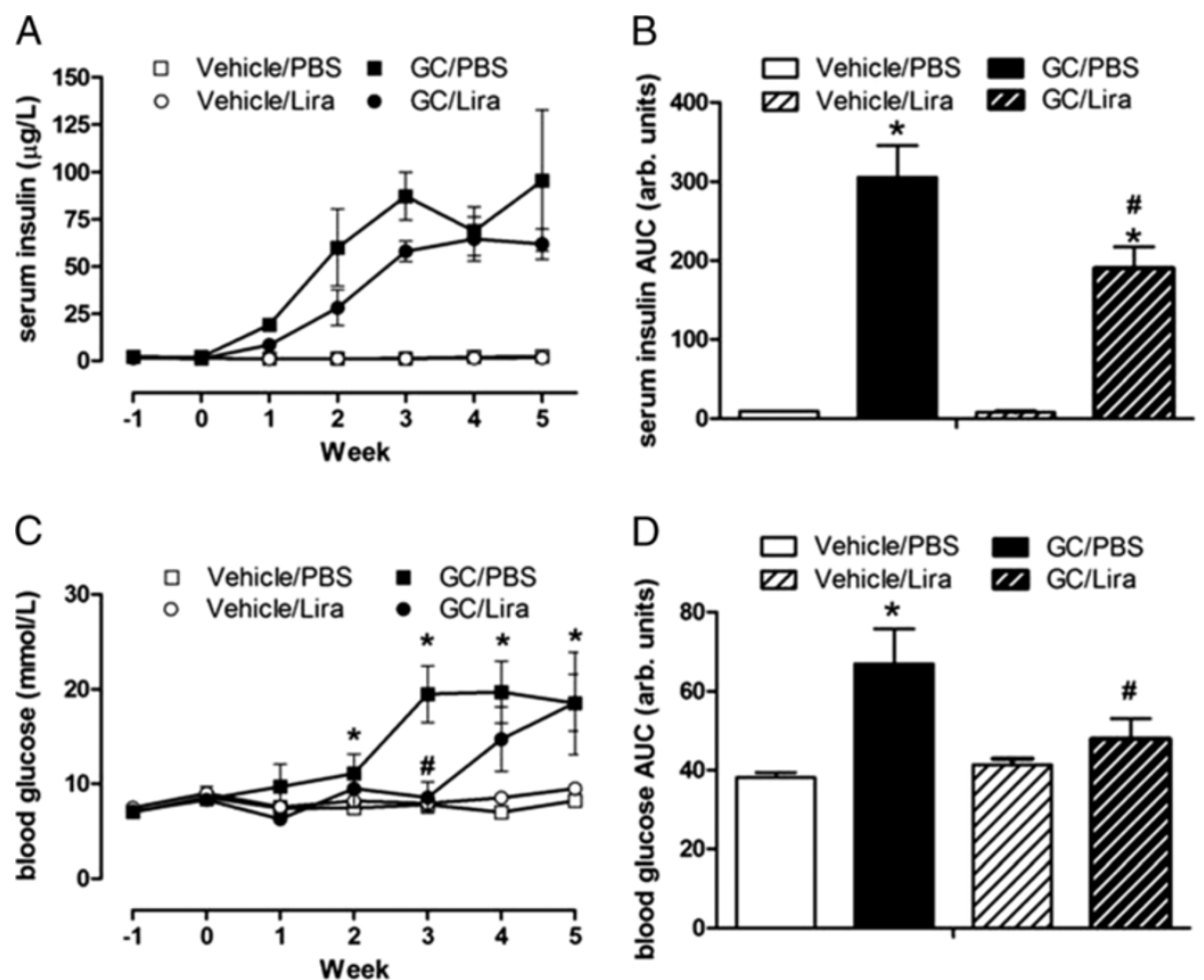

Figure 2 Once daily injections of liraglutide delay hyperinsulinemia and hyperglycemia in corticosterone-exposed mice. Male C57Bl/6J mice were treated with $1 \%$ ethanol (white squares and circles or white bars) or $100 \mu \mathrm{g} / \mathrm{ml}$ corticosterone (black squares and circles or black bars) via the drinking water together with once-daily injections of either PBS (squares or unstriped bars) or liraglutide at a final dose of $0.3 \mathrm{mg}$ per $\mathrm{kg}$ body weight (circles or striped bars) for five consecutive weeks $(n=6)$. Serum insulin levels (A and B) and blood glucose levels $(\mathbf{C}$ and $\mathbf{D})$ were determined every week in random-fed animals. Data is shown as mean \pm s.e.m. $A$ * denotes a significant $(p<0.05)$ effect of corticosterone treatment and a \# denotes a significant effect of liraglutide. 

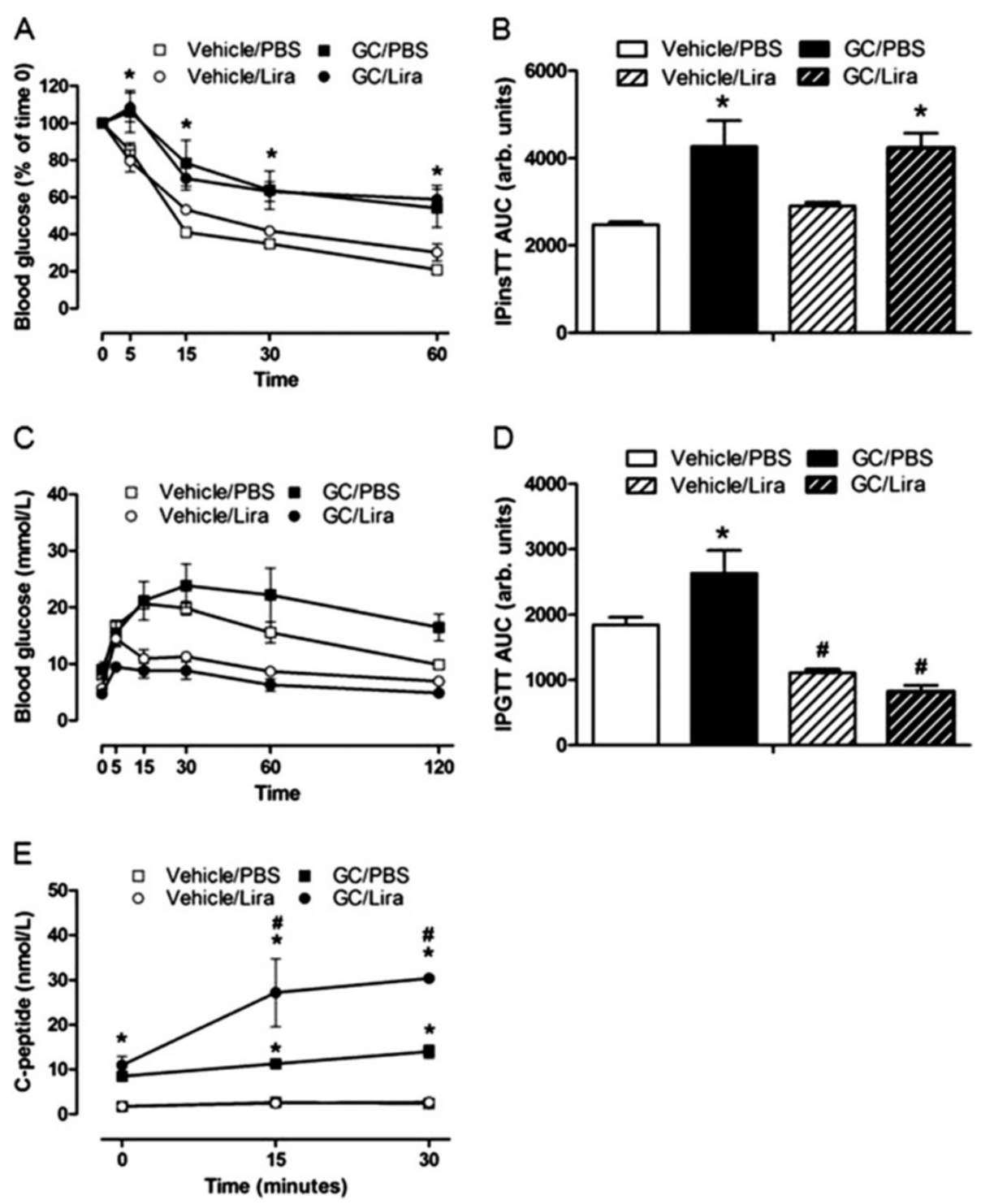

Figure 3 Once daily injections of liraglutide do not affect insulin sensitivity but improve glucose tolerance in corticosterone-exposed mice. Male C57Bl/6J mice were treated with $1 \%$ ethanol (white squares and circles or white bars) or $100 \mathrm{\mu g} / \mathrm{ml}$ corticosterone (black squares and circles or black bars) via the drinking water together with once-daily injections of either PBS (squares or unstriped bars) or liraglutide at a final dose of $0.3 \mathrm{mg}$ per $\mathrm{kg}$ body weight (circles or striped bars) for five consecutive weeks $(n=6)$. After four weeks of treatment insulin sensitivity was determined via an IPinsTT (A and B) and after five weeks of treatment glucose tolerance was determined via an IPGTT (C and D). During the IPGTT serum samples were collected and C-peptide levels were measured (E). Data is shown as mean \pm s.e.m. $A *$ denotes a significant $(p<0.05)$ effect of corticosterone treatment and a \# denotes a significant effect of liraglutide.

C-peptide levels were modestly increased in mice receiving corticosterone, $33 \pm 6 \%$ above basal at 15 minutes and $65 \pm 17 \%$ above basal at 30 minutes post glucose injection (Figure 3E). In contrast, the glucose-stimulated increase in serum C-peptide levels in mice treated with corticosterone and liraglutide was $149 \pm 30 \%$ and $178 \pm$ $23 \%$ above basal at 15 minutes and 30 minutes post glucose injection, respectively, indicating an improvement of beta-cell responsiveness to glucose by liraglutide treatment (Figure 3E).
Liraglutide has no effect on the increased beta-cell mass induced by corticosterone

To investigate possible structural changes in the endocrine pancreas in the present insulin-resistant mice model, we determined the beta- and alpha-cell masses in histological sections of pancreatic glands taken after five weeks of treatment with or without corticosterone in the absence or presence of liraglutide. The total pancreas weight was not altered among the groups (data not shown) nor was there any significant difference between the groups in 
the number of islets per pancreatic gland (Figures 4A and B). Instead there was an apparent islet hypertrophy in both groups of corticosterone-treated mice (Figure 4A). Morphometric analysis revealed that the relative and absolute beta-cell mass was significantly increased in pancreata obtained from corticosterone-treated mice irrespective of whether they were co-treated with liraglutide or not (Figures 4C-E). This increase in beta-cell mass is explained by enhanced islet-cell proliferation (most likely beta-cell proliferation) in corticosterone-treated mice. Figure 5A shows a higher distribution of Ki67-positive nuclei in both corticosterone-treated groups compared with their respective control groups. The islet-cell proliferation expanded significantly, reaching 2.6- and 2.4-fold increase in mice receiving corticosterone in the absence or presence of liraglutide treatment, respectively, compared to their

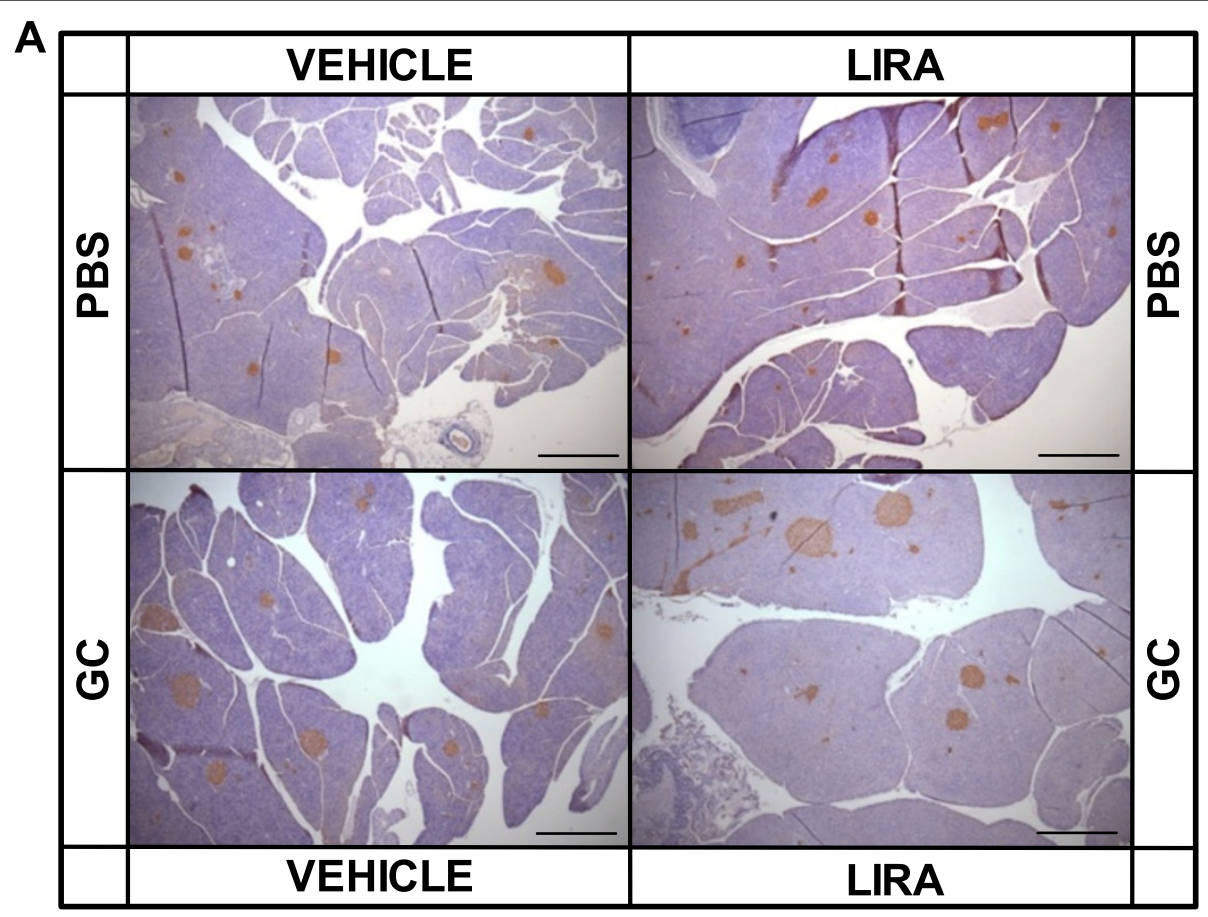

B

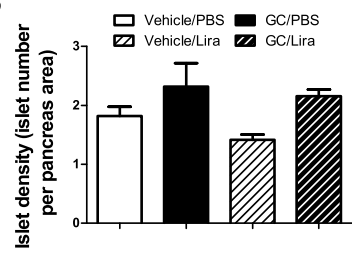

D

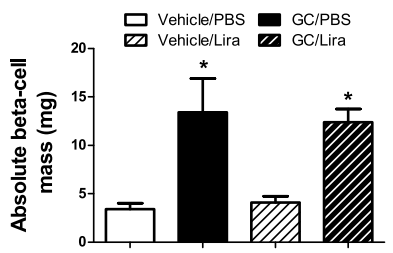

C
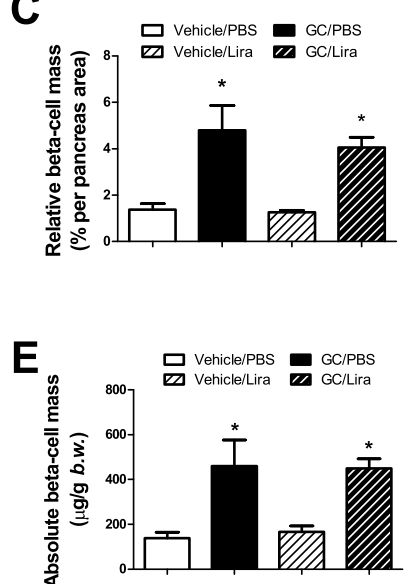

Figure 4 Once daily injections of liraglutide do not affect the increment of pancreatic beta-cells mass seen in corticosterone-exposed mice. Male C57BI/6J mice were treated with $1 \%$ ethanol (vehicle, white bars) or $100 \mu \mathrm{g} / \mathrm{ml}$ corticosterone (GC, black bars) via the drinking water together with once-daily injections of either PBS (unstriped bars) or liraglutide (Lira) at a final dose of $0.3 \mathrm{mg}$ per kg body weight (striped bars) for five consecutive weeks $(n=5-6)$. After treatment the pancreatic glands were dissected and processed for histology. Tissue sections were immunostained for insulin-positive cells (A). Morphometric analysis was used to determine islet density (B), relative beta-cell mass (C) and absolute beta-cell mass either expressed in $\mathrm{mg}(\mathbf{D})$ or as $\mu \mathrm{g}$ per $\mathrm{g}$ body weight (E). Images in (A) are representative pictures of insulin staining in the examined tissue $(40 \times$ magnification, bar represents $500 \mu \mathrm{m})$. Data is shown as mean \pm s.e.m. $A$ * denotes a significant $(p<0.05)$ effect of corticosterone treatment. 


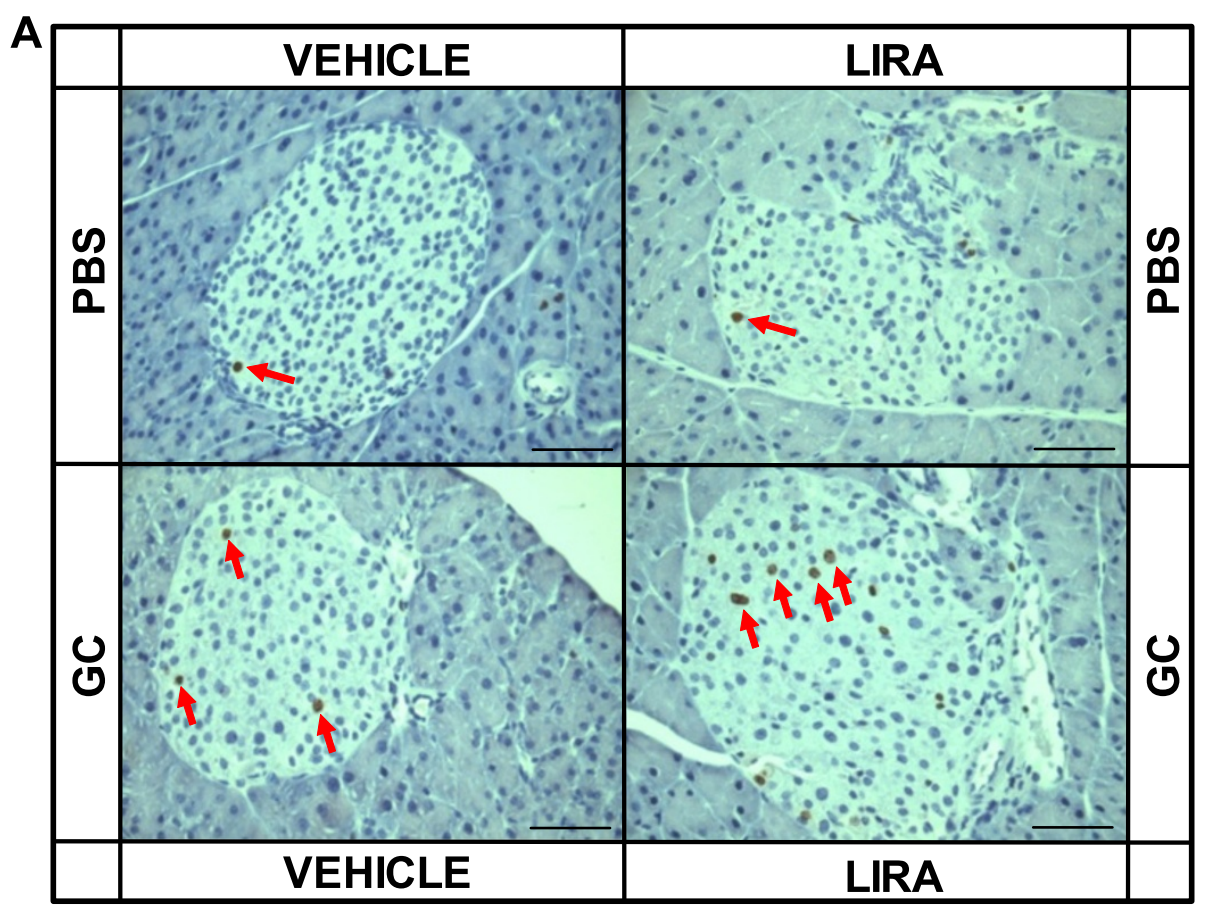

B

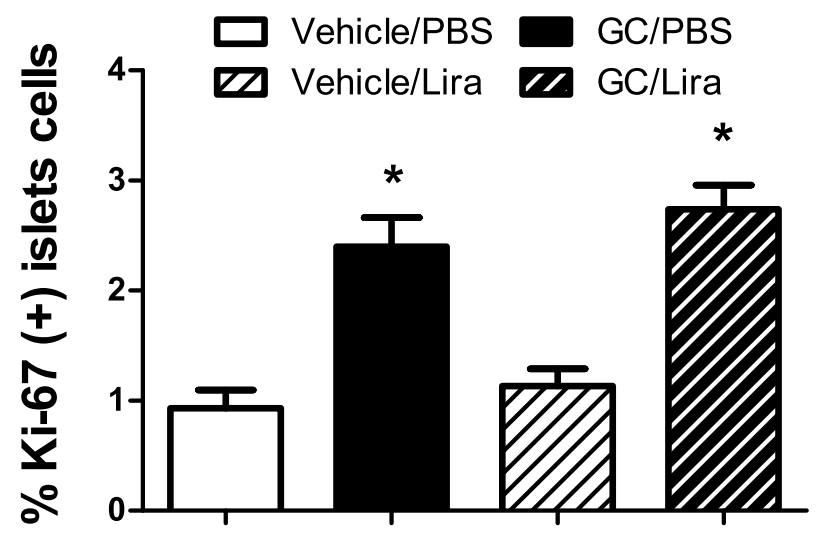

Figure 5 Once daily injections of liraglutide do not affect beta-cell proliferation in corticosterone-exposed mice. Male (57Bl/6J mice were treated with $1 \%$ ethanol (vehicle, white bars) or $100 \mu \mathrm{g} / \mathrm{ml}$ corticosterone (GC, black bars) via the drinking water together with once-daily injections of either PBS (unstriped bars) or liraglutide (Lira) at a final dose of $0.3 \mathrm{mg}$ per $\mathrm{kg}$ body weight (striped bars) for five consecutive weeks $(n=5-6)$. After treatment the pancreatic glands were dissected and processed for histology. Tissue sections were immunostained for Ki67-positive cells (A, red arrow). Morphometric analysis was used to the percentage of beta-cells that stained positive for Ki67 in the different mice cohorts (B). Images in (A) are representative pictures of Ki67 staining in the examined tissue (400 $\times$ magnification, bar represents $50 \mu \mathrm{m})$. Data is shown as mean \pm s.e.m. $A$ * denotes a significant $(p<0.05)$ effect of corticosterone treatment.

respective controls (Figure 5B). Our analysis of alpha-cell mass in histological sections of pancreata taken after five weeks of treatment, with or without corticosterone in the absence or presence of liraglutide, showed a significant increase in alpha-cell mass in corticosterone-treated mice (Figure 6). Liraglutide per se had no significant effect on any of the alpha-cell parameters evaluated, but seemed to cause a partial attenuation in the corticosterone-induced expansion of alpha-cell mass. Altogether, these data demonstrate that corticosterone administration to mice induces expansion of beta-cell and alpha-cell masses. Liraglutide exerted no positive or negative effect upon beta-cell mass per se or when combined with corticosterone. For alphacell mass, however, liraglutide treatment seems to result in a partial attenuation of the absolute alpha-cell mass expansion caused by corticosterone treatment.

\section{Discussion}

The main finding in this paper is that once daily injections with the DPP-4-resistant GLP-1R agonist liraglutide delay 
the development of hyperglycemia and promote beta-cell function in a mouse model of GC-induced metabolic syndrome. In this model, corticosterone is administrated via the drinking water. The model recapitulates in many respects the metabolic syndrome in humans, including body weight gain, dyslipidemia, ectopic lipid deposition and hypertension that occurs in conjunction with insulin resistance and glucose intolerance [20,21]. It should, however, be noted that - after five weeks of treatment with corticosterone - the mice became catabolic as evident by reduced body weight and that liraglutide was not able to fully protect against the diabetogenic effects of the GC in this setting. Thus, liraglutide fell short in providing full protection against corticosterone-induced glucose tolerance which of course limits the value of this study.

Nevertheless, it is clear that liraglutide postponed the appearance of obesity, hyperinsulinemia and hyperglycemia. It is also clear that administration of the GLP-1R agonist improved glucose clearance in an IPGTT. We could exclude the possibility that liraglutide caused any general reduction in peripheral GC sensitivity, as there were neither any differences between the effect of corticosterone on the glucose decay during the insulin tolerance test nor any impact of liraglutide on the reduced spleen size incurred by GC treatment. As nausea and vomiting are reported side effects during liraglutide treatment [28], this would be a potentially confounding factor in this study. However, we took care to avoid these side effects by slowly increasing the dosage until the final dose of liraglutide was reached and as indicated by the similar food intake in liraglutide-exposed mice as compared to mice treated with corticosterone or vehicle this dosing regime was successful. Liraglutide has previously been shown to efficaciously curb glucose intolerance and diabetes in both animal models [29] and in human T2DM patients [30]. However, its potential to counteract the diabetogenic effects of long-term steroid treatment has not previously been rigorously tested. Our findings show that liraglutide can delay hyperglycemia and avoid glucose intolerance that otherwise occurred as a consequence of steroid treatment. Thus, liraglutide may confer treatment benefits in patients at increased risk of developing steroid-induced diabetes. Liraglutide treatment was initiated simultaneously to corticosterone and our data supports that such an approach should be considered when handling patients with susceptibility towards steroidinduced diabetes, like subjects with a priori known insulin resistance [31], low insulin secretion capacity [12,32], genetic predisposition [33], or in patients with obesity [34]. Our findings support a recent case report where exenatide (another GLP-1R agonist) improved glucose control in patients with T2DM with worsened glycemic control caused by GC therapy [17], and yet another randomized, placebocontrolled, double-blind, crossover exploratory study in eight healthy men where it was shown that exenatide prevented $\mathrm{GC}$-induced glucose intolerance and islet dysfunction [16]. However, we think that the experimental data presented here advances the field in several aspects. First, the GC exposure time used in this study is extended to last for several weeks and in this aspect it better mimics the treatment time for patients prescribed GC-based drugs. Second, we show that once-daily injections with the DPP4-reistant GLP-1R agonist liraglutide can improve glycemic control in this model. Finally, as will be discussed below, we discriminate between two aspects of beta-cell adaptation to GC induced insulin resistance. Liraglutide treatment may also reduce stress responses in rodents [35], an effect that can contribute to the anti-diabetic observed in our study.

This study also reports on the ability of liraglutide to counteract GC-induced obesity. As expected, abdominal obesity developed in corticosterone-treated mice. Importantly, liraglutide delayed weight gain in corticosterone-treated mice, which was associated with reduced epididymal fat mass. A role of GLP-1 in obesity pathophysiology was suggested already in 1983 when it was shown that L-cell secretory activity was reduced in morbidly obese subjects [36]. Furthermore, obese patients with reduced post-prandial GLP-1 secretion displayed improved GLP-1 secretory activity upon weight loss [37]. This may be a consequence of lipotoxic actions directed towards the L-cells as these cells succumb by lipoapoptosis when exposed to palmitate in culture [38]. As GC therapy specifically induced visceral obesity, which is much more prone to induce insulin resistance than subcutaneous adiposity, it is additionally important that, as showed herein, liraglutide delays the progression towards obesity that otherwise relentlessly occurs during long-term GC treatment. These findings are in concordance with those reported in the LEAD (Liraglutide Effect and Action in Diabetes) studies series, where the weight loss after 30 week to 52 week treatment with liraglutide was $2-3 \mathrm{~kg}$ more than placebo treatment [39-44]. The weight loss occurred in the ratio 2:1 between fat and lean tissue, and the relative weight loss was greater in visceral fat compared with subcutaneous adipose tissue [45]. Also hepatic steatosis was reduced in patients during treatment with liraglutide [45], which supports our findings with decreased liver neutral lipid content in corticosterone-treated mice receiving liraglutide.

The present study also investigates the plasticity of the pancreatic beta-cell and alpha-cell mass in this setting of GC excess. There is a strong correlation between insulin sensitivity and insulin secretion such that reduced insulin sensitivity leads to augmented insulin secretion in order to maintain glucose control [21]. Compensatory hyperinsulinemia in response to $\mathrm{GC}$-induced reduction of insulin sensitivity may be attributable to increased beta-cell 


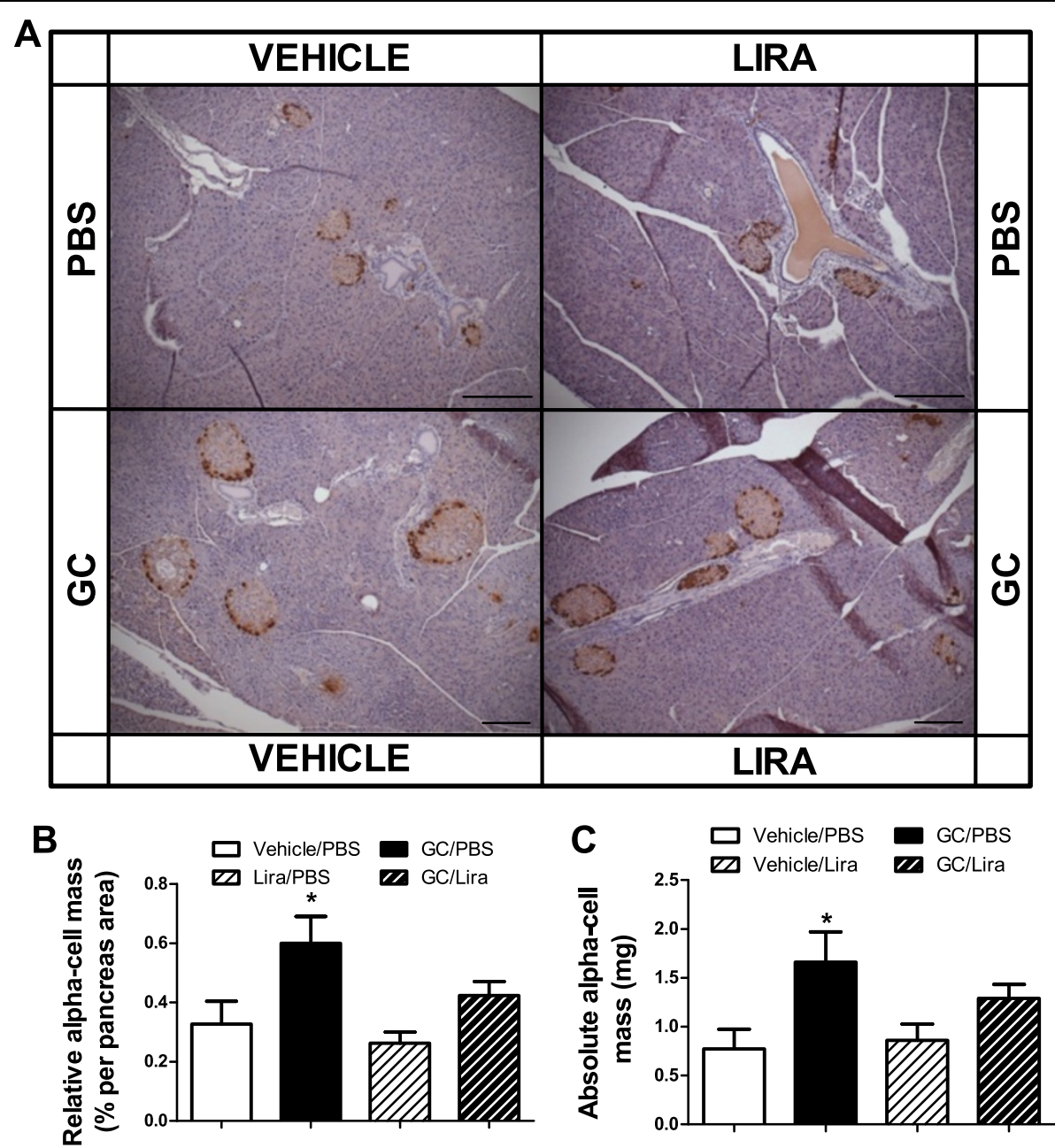

D

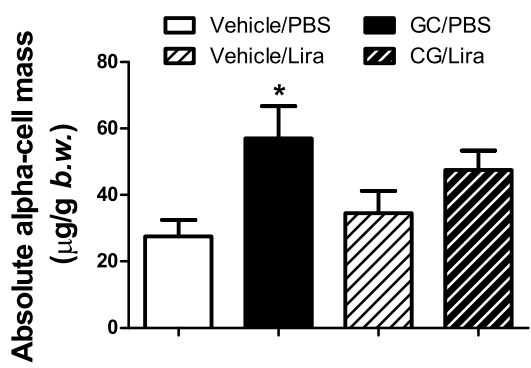

Figure 6 Corticosterone-exposed mice display increased alpha-cell mass. Male C57Bl/6J mice were treated with 1\% ethanol (white bars) or $100 \mathrm{mg} / \mathrm{ml}$ corticosterone (GC, black bars) via the drinking water together with once-daily injections of either PBS (unstriped bars) or liraglutide (Lira) at a final dose of $0.3 \mathrm{mg}$ per $\mathrm{kg}$ body weight (striped bars) for five consecutive weeks ( $n=5-6)$. After treatment, the pancreatic gland was dissected and processed for histology. Tissue sections were immunostained for glucagon-positive cells (A). Morphometric analysis was used to determine relative alpha-cell mass (B) and absolute alpha-cell mass either expressed in $\mathrm{mg}$ (C) or as $\mu \mathrm{g}$ per $\mathrm{g}$ body weight (D). Images in (A) are representative pictures of glucagon staining in the examined tissue $(100 \times$ magnification, bar represents $200 \mu m)$. Data is shown as mean \pm s.e.m. $A$ * denotes a significant $(p<0.05)$ effect of corticosterone treatment.

responsiveness to glucose and/or increased beta-cell mass $[24,28]$. In response to corticosterone treatment the betacell mass increased as a consequence, at least in part, of enhanced beta-cell proliferation. This observation is in agreement with the well-established reciprocal relationship between insulin sensitivity and pancreatic islet function. As insulin sensitivity decreases, the insulin secretion initially and adaptively increases in order to maintain the control of glucose homeostasis [46]. The compensatory increase of circulating insulin in response to the GC-imposed insulin 
resistance resulted from some beta-cell adaptation that includes augmented beta-cell function [47] and/or beta-cell mass [48]. Mice treated with corticosterone and liraglutide had the same impairment of insulin sensitivity as indicated by their similar capacity to clear glucose after an injection with insulin (Figures 3A and B). Mice treated with corticosterone with or without liraglutide also displayed the same increase in beta-cell mass (Figure 4), indicating that the beta-cell mass is primarily a reflection of the prevailing reduced insulin sensitivity and that liraglutide is not predominantly targeting insulin sensitivity.

An increased beta-cell mass in corticosterone-treated mice seems to be sufficient to maintain fasting normoglycemia, since this parameter was not affected after five weeks of treatment with the steroid. In the fed state, however, the insulin secretion in response to food intake was not enough to avoid the appearance of hyperglycemia, despite the higher beta-cell mass observed in corticosterone-treated groups. Liraglutide had no effect on beta-cell mass but displayed a marked ability to improve glucose clearance in response to a glucose challenge (IPGTT, Figure 3). These observations point towards an acute effect of liraglutide so that the optimal response to glucose challenge in both groups of mice treated with liraglutide is explained by short-term liraglutide effects. Our finding of augmented glucosestimulated C-peptide secretion in liraglutide-treated mice indicates a direct acute effect on pancreatic betacells that may turn beta-cells more competent to sense glucose. A puzzling observation is that liraglutide improved glucose tolerance also in vehicle-treated mice despite similar insulin sensitivity and glucosestimulated C-peptide secretion. Since C-peptide clearance occurs mainly through renal mechanisms, and GLP-1 is known to positively impact renal function [49] we cannot exclude that increased insulin secretion may have been masked by increased renal clearance of $\mathrm{C}$-peptide. Thus, the positive effects of liraglutide on glucose tolerance in this model of metabolic syndrome are best described by a direct effect on pancreatic betacells that seems to promote augmented exocytosis rather than promoting beta-cell proliferation and/or acting on peripheral insulin action. This means that liraglutide would be most effective if given at an early stage of T2DM when beta-cell mass is preserved. A recent publication reported on a positive association between incretin-based therapy and an expansion of pancreatic alpha-cell mass [50] in human post mortem specimens. However, we did not observe any increase in alpha-cell following 5 weeks of liraglutide treatment. In fact, liraglutide reduced the induction of alpha-cell mass seen in corticosterone-treated mice, although this finding did not reach statistical significance.

\section{Conclusions}

In this paper we show that the GLP-1R agonist liraglutide delays progression towards obesity and prandial hyperglycemia and efficiently enhances in vivo GSIS in a mouse model of GC-induced metabolic syndrome. Thus, GLP-1R agonists may offer advantages for patients suffering from steroid diabetes or glucose intolerance as a side effect of long-term GC therapy.

\section{Competing interest}

Å.S. has received research grants, consultancy fees, lecture honoraria, and fees for expert testimony from Novo Nordisk, the manufacturer of liraglutide. The other authors declare that they do not have any competing or financial interests.

\section{Authors' contribution}

$L F, \AA S S, A R$ and $H O$ conceived the hypothesis and designed the experiments. $L F, C S, P W$ and $H O$ performed the experiments. LF, CS, PW, AR and $H O$ analyzed the data. LF, ÅS, AR and HO wrote and edited the paper. All authors have read and approved the final version.

\section{Acknowledgements}

The authors thank the staff at the research center and the animal facility at Södersjukhuset for animal care. We are also grateful to Annika Mehlem and Annelie Falkevall at the Karolinska Institutet for advice on ORO staining. This study was supported by grants from the Lars Hiertas memorial foundation, Folksam Research Foundation and the Tore Nilsson Foundation. Henrik Ortsäter is funded by the Swedish Society for Medical Research. Liselotte Fransson is partly funded by KID (Karolinska Institutet, Faculty funds for partial funding of doctoral students). Alex Rafacho is partially funded by CNPq and the Instituto Nacional de Ciência e Tecnologia: Obesidade e Diabetes.

\section{Author details}

'Department of Clinical Science and Education, Södersjukhuset, Karolinska Institutet, Research Center Floor 3, 118 83, Stockholm, Sweden. ${ }^{2}$ Department of Physiological Sciences, Center of Biological Sciences, Federal University of Santa Catarina, Florianópolis, Brazil. ${ }^{3}$ Department of Internal Medicine, Södertälje Hospital, SE-152 86, Södertälje, Sweden. ${ }^{4}$ Department of Biochemistry and Molecular Biology, College of Medicine, University of South Alabama, Mobile, AL, USA. ${ }^{5}$ Research Unit, Södertälje Hospital, SE-152 86, Södertälje, Sweden.

Received: 27 September 2013 Accepted: 9 January 2014 Published: 14 January 2014

\section{References}

1. Schacke H, Docke WD, Asadullah K: Mechanisms involved in the side effects of glucocorticoids. Pharmacol Ther 2002, 96:23-43.

2. Shapiro AM, Lakey JR, Ryan EA, Korbutt GS, Toth E, Warnock GL, Kneteman $\mathrm{NM}$, Rajotte RV: Islet transplantation in seven patients with type 1 diabetes mellitus using a glucocorticoid-free immunosuppressive regimen. N Engl J Med 2000, 343:230-238.

3. Ohneda M, Johnson JH, Inman LR, Unger RH: GLUT-2 function in glucoseunresponsive $b$ cells of dexamethasone-induced diabetes in rats. $J$ Clin Invest 1993, 92:1950-1956.

4. Davani B, Portwood N, Bryzgalova G, Reimer MK, Heiden T, Ostenson CG, Okret S, Ahren B, Efendic S, Khan A: Aged transgenic mice with increased glucocorticoid sensitivity in pancreatic beta-cells develop diabetes. Diabetes 2004, 53(Suppl 1):S51-59.

5. Ling ZC, Khan A, Delauny F, Davani B, Ostenson CG, Gustafsson JA, Okret S, Landau BR, Efendic S: Increased glucocorticoid sensitivity in islet beta-cells: effects on glucose 6-phosphatase, glucose cycling and insulin release. Diabetologia 1998, 41:634-639.

6. Lambillotte C, Gilon P, Henquin JC: Direct glucocorticoid inhibition of insulin secretion. An in vitro study of dexamethasone effects in mouse islets. J Clin Invest 1997, 99:414-423.

7. Ullrich S, Berchtold S, Ranta F, Seebohm G, Henke G, Lupescu A, Mack AF, Chao CM, Su J, Nitschke R, et al: Serum- and glucocorticoid-inducible 
kinase 1 (SGK1) mediates glucocorticoid-induced inhibition of insulin secretion. Diabetes 2005, 54:1090-1099.

8. Linssen MM, van Raalte DH, Toonen EJ, Alkema W, van der Zon GC, Dokter WH, Diamant M, Guigas B, Ouwens DM: Prednisolone-induced beta cell dysfunction is associated with impaired endoplasmic reticulum homeostasis in INS-1E cells. Cell Signal 2011, 23:1708-1715.

9. Weinhaus AJ, Bhagroo NV, Brelje TC, Sorenson RL: Dexamethasone counteracts the effect of prolactin on islet function: implications for islet regulation in late pregnancy. Endocrinology 2000, 141:1384-1393.

10. Ranta F, Avram D, Berchtold S, Dufer M, Drews G, Lang F, Ullrich S: Dexamethasone induces cell death in insulin-secreting cells, an effect reversed by exendin-4. Diabetes 2006, 55:1380-1390.

11. Fernandez-Mejia C, Medina-Martinez O, Martinez-Perez L, Goodman PA: The human insulin gene contains multiple transcriptional elements that respond to glucocorticoids. Pancreas 1999, 18:336-341.

12. Wajngot A, Giacca A, Grill V, Vranic M, Efendic S: The diabetogenic effects of glucocorticoids are more pronounced in low- than in high-insulin responders. Proc Natl Acad Sci U S A 1992, 89:6035-6039.

13. Sadry SA, Drucker DJ: Emerging combinatorial hormone therapies for the treatment of obesity and T2DM. Nat Rev Endocrinol 2013, 9:425-433.

14. Torekov SS, Madsbad S, Holst JJ: Obesity - an indication for GLP-1 treatment? Obesity pathophysiology and GLP-1 treatment potential. Obes Rev 2011, 12:593-601.

15. Elliott RM, Morgan LM, Tredger JA, Deacon S, Wright J, Marks V: Glucagonlike peptide-1 (7-36)amide and glucose-dependent insulinotropic polypeptide secretion in response to nutrient ingestion in man: acute post-prandial and 24-h secretion patterns. J Endocrinol 1993, 138:159-166.

16. van Raalte DH, van Genugten RE, Linssen MM, Ouwens DM, Diamant M: Glucagon-like peptide-1 receptor agonist treatment prevents glucocorticoid-induced glucose intolerance and islet-cell dysfunction in humans. Diabetes Care 2011, 34:412-417.

17. Matsuo K, Nambu T, Matsuda Y, Kanai Y, Yonemitsu S, Muro S, Oki S: Evaluation of the effects of exenatide administration in patients with type 2 diabetes with worsened glycemic control caused by glucocorticoid therapy. Int Med 2013, 52:89-95.

18. Shyangdan D, Cummins E, Royle P, Waugh N: Liraglutide for the treatment of type 2 diabetes. Health Technol Assess 2011, 15(Suppl 1):77-86.

19. Montanya E: A comparison of currently available GLP-1 receptor agonists for the treatment of type 2 diabetes. Expert Opin on Pharmacother 2012, 13:1451-1467.

20. Fransson L, Franzen S, Rosengren V, Wolbert P, Sjöholm $\AA$, Ortsäter H: b-cell adaptation in a mouse model of glucocorticoid-induced metabolic syndrome. J Endocrinol 2013, 219:231-241.

21. Karatsoreos IN, Bhagat SM, Bowles NP, Weil ZM, Pfaff DW, McEwen BS: Endocrine and physiological changes in response to chronic corticosterone: a potential model of the metabolic syndrome in mouse. Endocrinology 2010, 151:2117-2127.

22. Mehlem A, Hagberg CE, Muhl L, Eriksson U, Falkevall A: Imaging of neutral lipids by oil red $\mathrm{O}$ for analyzing the metabolic status in health and disease. Nat Protoc 2013, 8:1149-1154.

23. Rafacho A, Ribeiro DL, Boschero AC, Taboga SR, Bosqueiro JR: Increased pancreatic islet mass is accompanied by activation of the insulin receptor substrate-2/serine-threonine kinase pathway and augmented cyclin D2 protein levels in insulin-resistant rats. Int J of Exp Pathol 2008, 89:264-275

24. Rafacho A, Cestari TM, Taboga SR, Boschero AC, Bosqueiro JR: High doses of dexamethasone induce increased b-cell proliferation in pancreatic rat islets. Am J Physiol Endocrinol Metab 2009, 296:E681-689.

25. Lee RS, Tamashiro KL, Yang X, Purcell RH, Harvey A, Willour VL, Huo Y, Rongione M, Wand GS, Potash JB: Chronic corticosterone exposure increases expression and decreases deoxyribonucleic acid methylation of Fkbp5 in mice. Endocrinology 2010, 151:4332-4343.

26. Patel R, Patel M, Tsai R, Lin V, Bookout AL, Zhang Y, Magomedova L, Li T, Chan JF, Budd C, et al: LXRb is required for glucocorticoid-induced hyperglycemia and hepatosteatosis in mice. J Clin Invest 2011, 121:431-441.

27. Hagberg CE, Mehlem A, Falkevall A, Muhl L, Fam BC, Ortsater H, Scotney P, Nyqvist $D$, Samen E, Lu L, et al: Targeting VEGF-B as a novel treatment for insulin resistance and type 2 diabetes. Nature 2012, 490:426-430.

28. Hallberg $P$, Schwan S, Melhus H: Liraglutide for weight loss in obese people. Lancet 2010, 375:551. author reply 552-553.
29. Wu L, Olverling A, Fransson L, Ortsäter H, Kappe C, Gao X, Sjöholm Å: Early intervention with liraglutide improves glucose tolerance without affecting islet microcirculation in young Goto-Kakizaki rats. Regul Pept 2012, 177:92-96.

30. Perry CM: Liraglutide: a review of its use in the management of type 2 diabetes mellitus. Drugs 2011, 71:2347-2373.

31. Larsson $H$, Ahren B: Insulin resistant subjects lack islet adaptation to short-term dexamethasone-induced reduction in insulin sensitivity. Diabetologia 1999, 42:936-943.

32. Grill V, Pigon J, Hartling SG, Binder C, Efendic S: Effects of dexamethasone on glucose-induced insulin and proinsulin release in low and high insulin responders. Metabolism 1990, 39:251-258.

33. Henriksen JE, Alford F, Ward GM, Beck-Nielsen H: Risk and mechanism of dexamethasone-induced deterioration of glucose tolerance in non-diabetic first-degree relatives of NIDDM patients. Diabetologia 1997, 40:1439-1448.

34. Besse C, Nicod N, Tappy L: Changes in insulin secretion and glucose metabolism induced by dexamethasone in lean and obese females. Obes Res 2005, 13:306-311.

35. Gil-Lozano M, Romani-Perez M, Outeirino-Iglesias V, Vigo E, Brubaker PL, Gonzalez-Matias LC, Mallo F: Effects of prolonged exendin-4 administration on hypothalamic-pituitary-adrenal axis activity and water balance. Am J Physiol Endocrinol Metab 2013, 304:E1105-1117.

36. Holst JJ, Schwartz TW, Lovgreen NA, Pedersen O, Beck-Nielsen H: Diurnal profile of pancreatic polypeptide, pancreatic glucagon, gut glucagon and insulin in human morbid obesity. Int J of Obes 1983, 7:529-538.

37. Verdich C, Toubro S, Buemann B: Lysgard madsen J, juul holst J, astrup a: the role of postprandial releases of insulin and incretin hormones in meal-induced satiety-effect of obesity and weight reduction. Int J Obes Relat Metab Disord 2001, 25:1206-1214.

38. Kappe C, Patrone C, Holst JJ, Zhang Q, Sjoholm A: Metformin protects against lipoapoptosis and enhances GLP-1 secretion from GLP-1producing cells. J of Gastroenterol 2013, 48:322-332.

39. Russell-Jones D, Vaag A, Schmitz O, Sethi BK, Lalic N, Antic S, Zdravkovic M, Ravn GM, Simo R, Liraglutide E, Action in Diabetes 5 met SUSG: Liraglutide vs insulin glargine and placebo in combination with metformin and sulfonylurea therapy in type 2 diabetes mellitus (LEAD-5 met + SU): a randomised controlled trial. Diabetologia 2009, 52:2046-2055.

40. Buse JB, Sesti G, Schmidt WE, Montanya E, Chang CT, Xu Y, Blonde L, Rosenstock J, Liraglutide Effect Action in Diabetes-6 Study G: Switching to once-daily liraglutide from twice-daily exenatide further improves glycemic control in patients with type 2 diabetes using oral agents. Diabetes Care 2010, 33:1300-1303.

41. Marre M, Shaw J, Brandle M, Bebakar WM, Kamaruddin NA, Strand J, Zdravkovic M, Le Thi TD, Colagiuri S, group L-Ss: Liraglutide, a once-daily human GLP-1 analogue, added to a sulphonylurea over 26 weeks produces greater improvements in glycaemic and weight control compared with adding rosiglitazone or placebo in subjects with Type 2 diabetes (LEAD-1 SU). Diabet Med 2009, 26:268-278.

42. Garber A, Henry R, Ratner R, Garcia-Hernandez PA, Rodriguez-Pattzi H, Olvera-Alvarez I, Hale PM, Zdravkovic M, Bode B, Group L-S: Liraglutide versus glimepiride monotherapy for type 2 diabetes (LEAD-3 Mono): a randomised, 52-week, phase III, double-blind, parallel-treatment trial. Lancet 2009, 373:473-481.

43. Zinman B, Gerich J, Buse JB, Lewin A, Schwartz S, Raskin P, Hale PM, Zdravkovic M, Blonde L, Investigators L-S: Efficacy and safety of the human glucagon-like peptide-1 analog liraglutide in combination with metformin and thiazolidinedione in patients with type 2 diabetes (LEAD-4 Met + TZD). Diabetes Care 2009, 32:1224-1230.

44. Nauck M, Frid A, Hermansen K, Shah NS, Tankova T, Mitha IH, Zdravkovic M, During M, Matthews DR, Group L-S: Efficacy and safety comparison of liraglutide, glimepiride, and placebo, all in combination with metformin, in type 2 diabetes: the LEAD (liraglutide effect and action in diabetes)-2 study. Diabetes Care 2009, 32:84-90.

45. Jendle J, Nauck MA, Matthews DR, Frid A, Hermansen K, During M, Zdravkovic M, Strauss BJ, Garber AJ, Lead, Groups L-S: Weight loss with liraglutide, a once-daily human glucagon-like peptide-1 analogue for type 2 diabetes treatment as monotherapy or added to metformin, is primarily as a result of a reduction in fat tissue. Diab Obes Metab 2009, 11:1163-1172

46. Kahn SE, Prigeon RL, McCulloch DK, Boyko EJ, Bergman RN, Schwartz MW, Neifing JL, Ward WK, Beard JC, Palmer JP, et al: Quantification of the 
relationship between insulin sensitivity and beta-cell function in human subjects. Evidence for a hyperbolic function. Diab 1993, 42:1663-1672.

47. Rafacho A, Marroqui L, Taboga SR, Abrantes JL, Silveira LR, Boschero AC, Carneiro EM, Bosqueiro JR, Nadal A, Quesada I: Glucocorticoids in vivo induce both insulin hypersecretion and enhanced glucose sensitivity of stimulus-secretion coupling in isolated rat islets. Endocrinology 2010, 151:85-95.

48. Rafacho A, Abrantes JL, Ribeiro DL, Paula FM, Pinto ME, Boschero AC, Bosqueiro JR: Morphofunctional alterations in endocrine pancreas of short- and long-term dexamethasone-treated rats. Horm Metab Res 2011, 43:275-281.

49. Filippatos TD, Elisaf MS: Effects of glucagon-like peptide-1 receptor agonists on renal function. World J of Diab 2013, 4:190-201.

50. Butler AE, Campbell-Thompson M, Gurlo T, Dawson DW, Atkinson M, Butler PC: Marked expansion of exocrine and endocrine pancreas with incretin therapy in humans with increased exocrine pancreas dysplasia and the potential for glucagon-producing neuroendocrine tumors. Diabetes 2013, 62:2595-2604.

doi:10.1186/1758-5996-6-3

Cite this article as: Fransson et al: Liraglutide counteracts obesity and glucose intolerance in a mouse model of glucocorticoid-induced metabolic syndrome. Diabetology \& Metabolic Syndrome 2014 6:3.

\section{Submit your next manuscript to BioMed Central and take full advantage of:}

- Convenient online submission

- Thorough peer review

- No space constraints or color figure charges

- Immediate publication on acceptance

- Inclusion in PubMed, CAS, Scopus and Google Scholar

- Research which is freely available for redistribution 